\title{
Memorias, violencias, cotidianidades y reconfiguraciones temporales en cuerpos femeninos*
}

VIOLENCE, MEMORIES, EVERYDAY LIFE AND TEMPORARY CONFIGURATIONS

OF THE FEMALE BODY

MEMÓRIAS, VIOLÊNCIA, COTIDIANIDADES E RECONFIGURAÇÕES

TEMPORÁRIOS EM CORPOS FEMININOS

\section{Catalina Cortés Severino**}

Cuadernos de Música, Artes Visuales y Artes Escénicas

/ Volumen 10 - Número 1 / enero - junio de 2015 /

ISSN 1794-6670/ Bogotá, D.C., Colombia / pp. 79-94

Fecha de recepción: 2014 | Fecha de aceptación: 2014

| Disponible en línea: 29 de mayo de 2015. Encuentre

este artículo en http://cuadernosmusicayartes.javeriana.

edu.co/doi:10.11144/Javeriana.mavae10-1.mvcr

*Artículo de investigación. Resultado de la tesis doctoral Políticas, éticas y estéticas de la memoria en la Colombia contemporánea, Universidad de Siena

**Profesora de la Pontificia Universidad Javeriana, Departamento de Estudios Culturales 


\section{Resumen}

Este proyecto es el resultado de un acercamiento audiovisual y etnográfico a diferentes escenarios de memorias de la violencia de la Comunidad de Paz de San José de Apartadó y la Organización de Mujeres Wayuu Munsurat. Este artículo se concentra principalmente en cómo la cotidianidad de las mujeres que viven en medio de los escenarios de terror y en contextos de violencias estructurales, materiales y cotidianas guarda dentro de sí la intimidación del acontecimiento y cómo esta a su vez, estructura el presente silenciosa y fantasmalmente. Este estudio, por lo tanto, hizo un acercamiento a través de la etnografía, la crítica cultural, las prácticas audiovisuales y la aproximación sensorial a la forma en que la violencia es experimentada en la vida cotidiana, no solo en cuanto a los espacios de la muerte y la destrucción sino en cuanto a los modos en que las mujeres padecen, perciben, persisten y resisten esas violencias, recuerdan sus pérdidas y les hacen duelo, pero también al modo en que las absorben, las sobrellevan, las articulan a su cotidianidad, la usan para su beneficio, la evaden o simplemente coexisten con ellas.

Palabras clave: Etnografía de la cotidianidad; violencia; procesos de subjetivación política; perspectiva de género; movimientos sociales; intimidad, temporalidades

\begin{abstract}
This project is the outcome of an audiovisual and ethnographic approach process to different violence memory scenarios of the Peace Community at San José de Apartadó and Munsurat Wayuu Women Organization.

This article focuses primarily on how the daily life of women holds within itself, the violence that structures the present and silent ghostly, so they live between terror scenes of everyday contexts and structural and physical violence.
\end{abstract}

Keywords: Everyday life ethnography; violence; political subjectivation processes; gender perspective; social movements; privacy;

temporalities

\section{Resumo}

Este projecto é o resultado de um processo de abordagem audiovisual e etnográfica de diferentes cenários de memórias da violência da Comunidade de Paz de San José de Apartadó e Munsurat Wayuu Women Organization.

Este artigo concentra-se principalmente sobre como o cotidiano de mulheres que vivem no meio das cenas de terror e em situações do quotidiano e da violência estrutural, materiais, tem dentro de si a violência do evento e este por sua vez estruturas do presente e em silêncio fantasmagórica

Palavras-chave: Etnografia da vida cotidiana; a violencia; processos de subjetivação política; perspectiva de gênero; movimentos sociais: privacidade; temporalidades 
Hace falta que las materias sedimentadas del pasado se muevan hacia nuevas construcciones de sentido, que entren en conexiones activas y transformadoras con los procesos de subjetividad que se inventan contingentemente en los márgenes no codificados de las representaciones de época.

Nelly Richard

Este proyecto es el resultado de un proceso de acercamiento audiovisual y etnográfico a diferentes escenarios de memorias de la violencia de la Comunidad de Paz de San José de Apartadó y la Organización de Mujeres Wayuu Munsurat. Mi aproximación a los escenarios de memorias desplegados por dichos movimientos ha sido a través de sus formas de re-habitar los espacios y los cuerpos tocados por la violencia; de la puesta en escena de los duelos íntimos y colectivos, y de las prácticas y poéticas del recordar y de su dimensión política, entendiendo todas estas desde las prácticas cotidianas de resistencia y de resignificación de los espacios de devastación.

Este artículo busca aproximarse a las mujeres no desde su identidad cultural y social sedimentada, sino más bien desde las prácticas que reagencian y reinventan el habitar de los cuerpos tocados por las diferentes violencias, deteniéndonos en las prácticas cotidianas transformativas que les permiten ir resignificando sus heridas, los espacios que habitan y resistir a las identidades que las sujetan. Se trata, en muchos casos, de prácticas de re-significación banales, imperceptibles, escurridizas, difíciles de nombrar, fijar o identificar, pero donde la cotidianidad de las mujeres que viven en medio de estos espacios, desde sus contextos específicos y contingencias emergentes, dan lugar a otras posibilidades de futuros pensados y sentidos, a partir de otras relaciones con el pasado y el presente -a veces efímeras y, a veces, más duraderas-.

Con base en estos planteamientos, intenté explorar los vacíos, los residuos y las fracturas del discurso de normalización social y política de la transición, para develar otras formas de ser-en-el-tiempo a través de diferentes procesos de subjetivación e identificación que están reconfigurando el orden establecido. Por medio de una indagación materialista y cotidiana en el contexto amplio de la violencia, enfatizo en un descenso al registro etnográfico para seguir los ritmos, rumores, desvíos y eventos que transcurren en el terreno inestable de las subjetividades e identidades. La pregunta por la reconstrucción de estas últimas, mediante su incorporación en los dispositivos estatales -por ejemplo, el reclamo a la reparación y la desmovilización-o a través de itinerarios impredecibles -por ejemplo, mujeres indígenas en las que se ve una reconfiguración de género a causa del desplazamiento- sitúa el interés investigativo en el terreno de la complejidad y no da garantía de estos arreglos (fotografía 2).

En las últimas décadas hemos visto cómo, en América Latina, el concepto de memoria se ha constituido en un principio de conocimiento y en un terreno de lucha política en la democratización de los países -por ejemplo, en el tránsito de las dictaduras a la democracia en Chile y Argentina-. En Colombia, se ha referido a la búsqueda de salidas al conflicto armado interno, posterior a los acuerdos de paz. Esto nos explica cómo las instituciones son entidades históricas (Das, 2008) y filosóficas (Derrida, 2002) que están definiendo y proponiendo concepciones temporales (dictadura/pos-dictadura, conflicto/pos-conflicto, apartheid/pos-apartheid) y, consecuentemente, ciertas políticas del tiempo, no solo en cuanto al pasado sino también en 


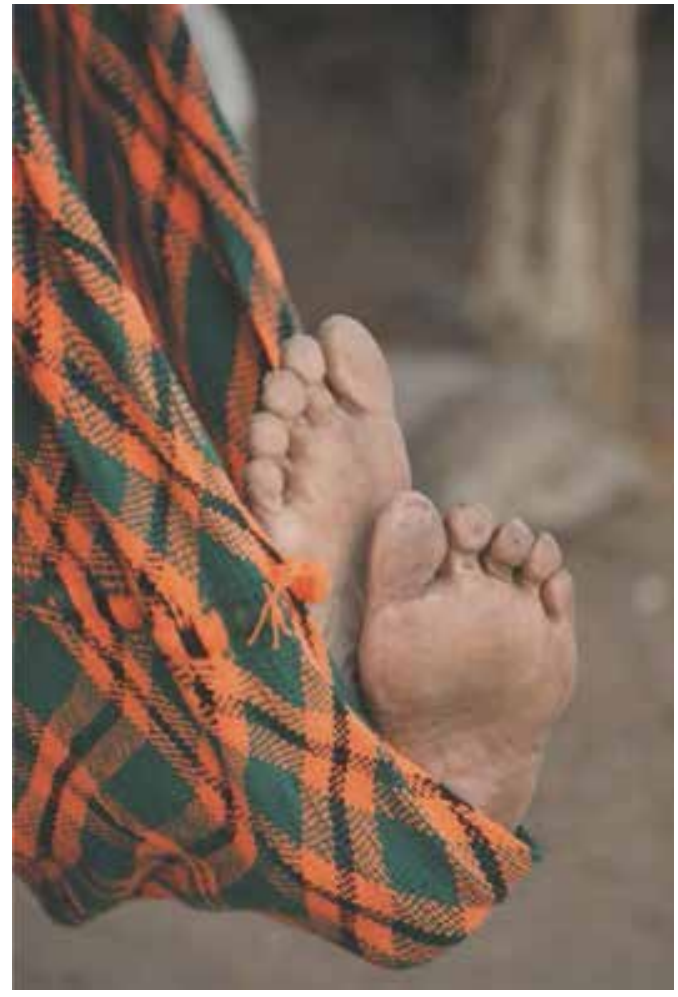

Fotografía 1. Autora Catalina Cortés Severino. Proyecto: Memorias, violencias, cotidianidades y reconfiguraciones temporales en cuerpos femeninos.

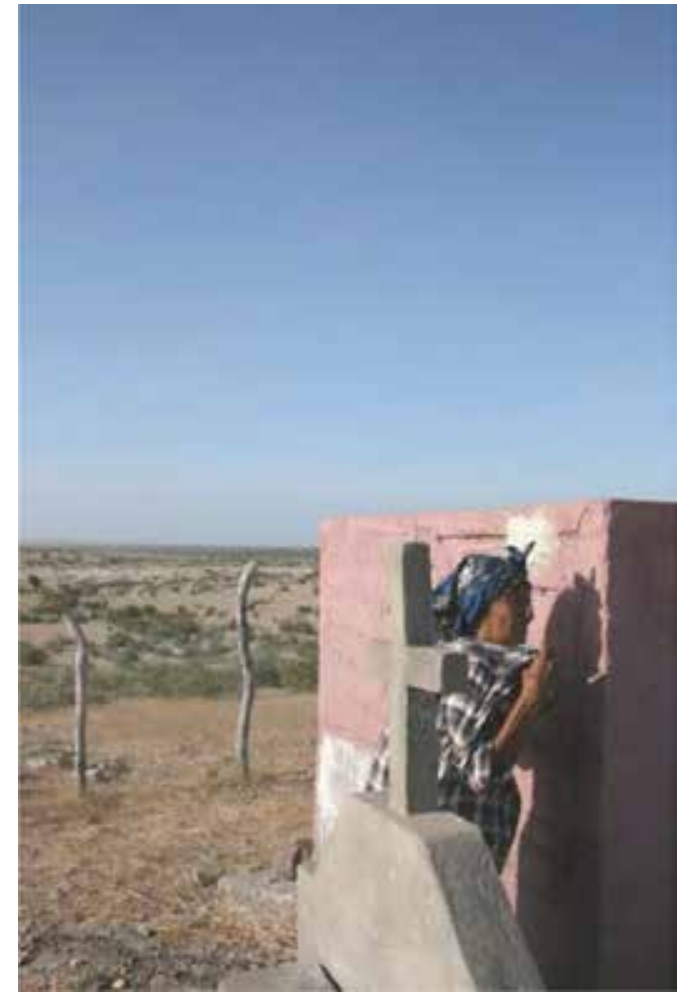

Fotografía 2. Autora Catalina Cortés Severino. Proyecto: Memorias, violencias, cotidianidades y reconfiguraciones temporales en cuerpos femeninos.

cuanto a la construcción de futuro dentro de ciertos significados, deseos y sentires. De esta manera, la relación entre memoria y democracia, implantada en las últimas décadas por algunos estados, se basa en las ideas de 'justicia', 'reconciliación' y 'reparación', dentro de marcos institucionales donde se busca principalmente el consenso, la normalización y el 'cierre' de la crisis que se ha vivido.

Lo que acá estoy llamando institucionalización del tiempo se basaría principalmente en el modo en que las instituciones despliegan sus políticas del tiempo sobre los cuerpos, construyendo y determinando su pasado, presente y futuro, con implicaciones materiales y simbólicas.

Chakrabarty (2000), en su argumento sobre la 'conciencia antihistórica', nos recuerda la necesidad de articular diferentes modos de ser-en-el-mundo 'fuera' del código dominante de la historia secular moderna:

Esto es en parte porque las mismas narrativas frecuentemente demuestran una conciencia antihistórica, es decir, donde ellos necesitan posiciones de sujeto y configuraciones de memoria que interroguen y desestabilice el sujeto que habla en nombre de la historia. (p. 37)

De esta manera, estas otras formas de ser-en-el-tiempo abren la posibilidad para la intersección de múltiples temporalidades donde convive el tiempo institucional, el de la 'transición' y otras temporalidades no históricas.

Los periodos llamados de transición se refieren a ese paso intermedio que hay entre las dictaduras y las democracias, entre los conflictos y los pos-conflictos, pero ese cambio casi siempre ha sido puesto en escena como una 'nueva época', pacífica, regeneradora, reparado- 
ra, tras un periodo violento, de terror y caótico. A diferencia de esta perspectiva, mi acercamiento a la transición se sitúa en ese tercer espacio que no acepta los dualismos implícitos en las transiciones de la dictadura a la democracia, de la violencia a la paz, del conflicto al pos-conflicto, de la pérdida a la victoria, sino que, más bien, pretende ubicarse en esos intervalos donde es posible generar aproximaciones que permitan movilizarse entre la pérdida y la recuperación, los espectros y los vivos, el pasado y el futuro, las ausencias y las presencias, lo cual complejiza estos escenarios y, al mismo tiempo, permite imaginar posibilidades de futuros, pasados y presentes donde el espacio del duelo y la pérdida son el punto de partida y no tienen como objetivo traspasar, eliminar, negar o ignorar.

\section{HACIA UNA ETNOGRAFÍA DE LAS RUINAS: SUBJETIVIDADES, TIEMPO Y VIOLENCIA}

Esta investigación se sitúa en una propuesta tanto teórica como metodológica que propone el fragmento y la ruina como material de trabajo, por medio de la articulación entre el análisis sociocultural y los lenguajes estéticos. La aproximación a lo temporal a través de la imagen dialéctica ha conducido a un acercamiento no-narrativo y no-textual de la historia a través de imágenes, donde la interposición de tiempos y los seguimientos a las huellas -lo que queda detrás, al lado o por fuera de la imagen- va evocando las fisuras y fragmentos que componen las ruinas. Así, al mismo tiempo, la ruina es una metáfora evocativa con una potencia crítica.

La ubicación entre lo material y lo metafórico de la ruina permite entrar en las espirales de tiempo y ver así las huellas, fisuras, deseos y fracturas que componen el presente -a diferencia de las ruinas de los viajeros del siglo XIX, en las cuales veían algunos lugares para rescatar la 'identidad nacional', 'la esencia originaria' del orgullo nacionalista o la justificación que orientara la colonización de tierras consideradas atrasadas, incultas o bárbaras-.

La ruina de Benjamin (1997) es un concepto metafórico que nos permite acercarnos a las materialidades del 'tiempo del ahora', no con un pasado perdido y deseado nostálgicamente, sino, por el contrario, con un pasado que hace parte del devenir. Las gramáticas del sentido de lo temporal de la ruina se ubican en las prácticas de la vida cotidiana y sus formaciones sociales. Las ruinas, como lo expresa Stoller (2008, p. 194), tienen que ver principalmente con 'lo que queda', con las marcas y sedimentaciones que van dejando las diferentes violencias, con el 'después' material y social de estructuras, sensibilidades y cosas. Las ruinas se alejan completamente de ser elementos contemplativos y pasan a ser el lugar desde donde se puede aproximar críticamente al presente.

Desde esta perspectiva, esta propuesta parte de un sentido de lo temporal que no se rige por la determinación del pasado sobre el presente, sino que parte de repensar la relación bajo la cual un número de imágenes del pasado se unen al 'ahora' y, así, configuran una constelación de sentido que expresa la contingencia radical del presente y de los futuros imaginados que permiten la comprensión del mismo. Así, las ruinas condensan sentidos alternativos de la historia.

La propuesta de la ruina como aproximación estética y política parte del 'Giro estético' del que nos habla Jean Franco (1999), donde se puede crear un espacio que permita ver las profundas huellas que todavía permanecen y los posibles futuros por venir o aquellos que ya se han ido. 
Este estudio ha partido del análisis de las condiciones y los contextos sociopolíticos de este momento coyuntural de 'transición' y ha llegado hasta la estética como modo creativo de alterar los espacios y los tiempos. Con ello retorna a la política, pues, al alterar los tiempos y espacios y exponer un pensamiento creativo, se trata ya de una intervención política en lo real (Rancière, 2010). Así, las políticas y estéticas de la ruina están totalmente entrelazadas con las reconfiguraciones de las gramáticas del sentido de lo temporal, al mismo tiempo que desconfiguran las gramáticas que ha establecido la institucionalización del tiempo.

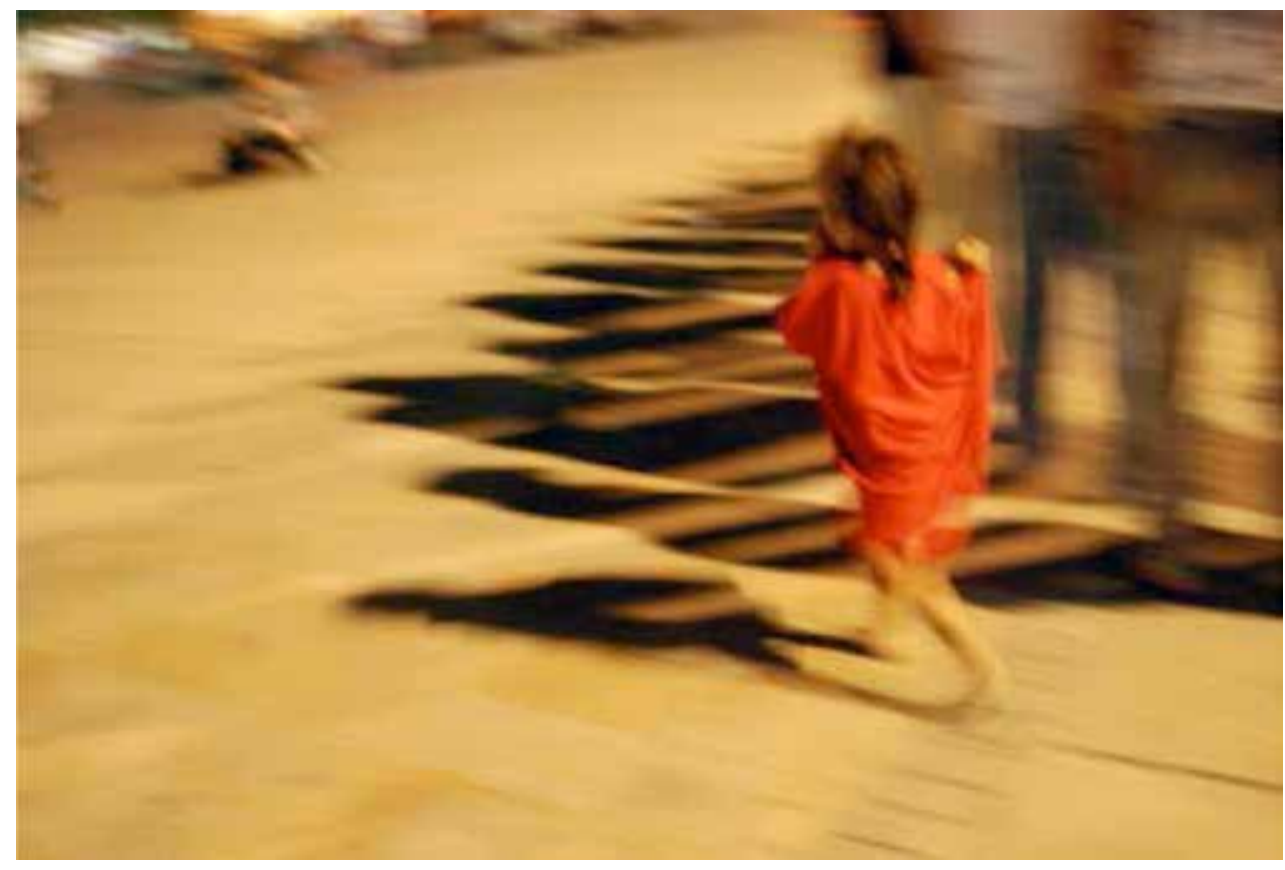

Fotografía 3. Catalina Cortés Severino. Proyecto: Memorias, violencias, cotidianidades y reconfiguraciones temporales en cuerpos femeninos.

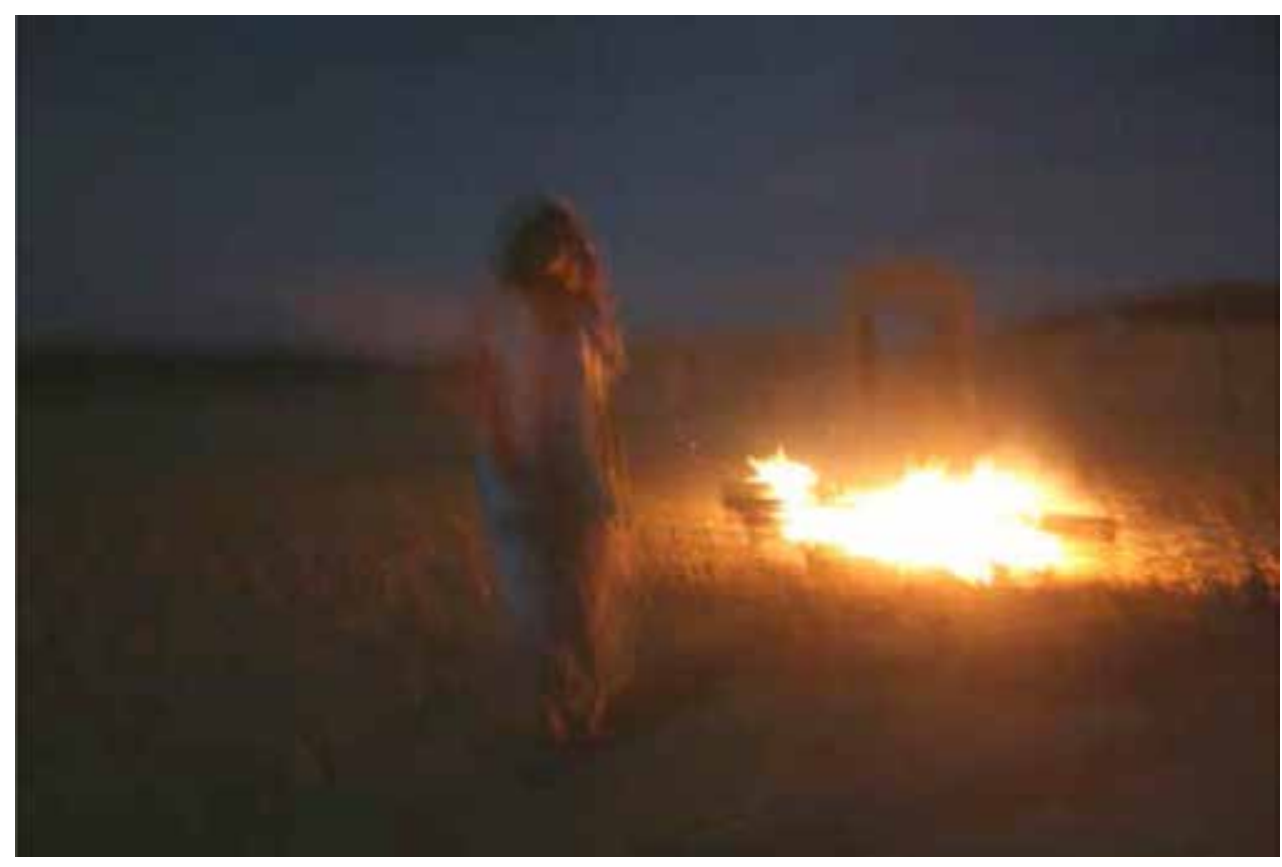

Fotografía 4. Catalina Cortés Severino. Proyecto: Memorias, violencias, cotidianidades y reconfiguraciones temporales en cuerpos femeninos. 


\section{PARTIDAS DESDE LA IMAGEN-RUINA EN CUERPOS FEMENINOS}

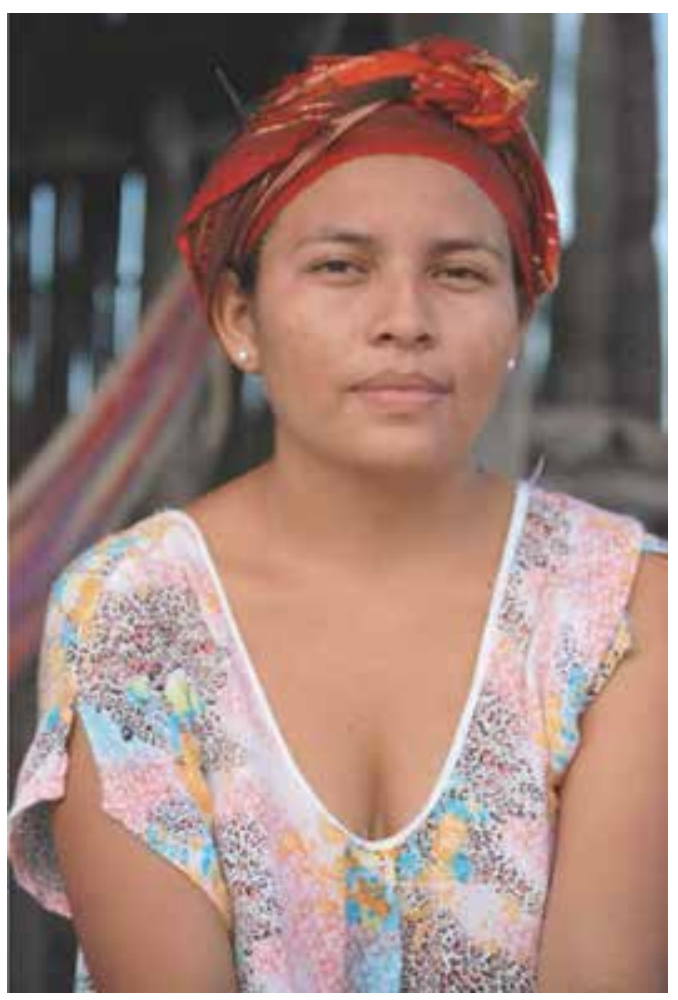

Fotografía 5. Catalina Cortés Severino. Proyecto: Memorias, violencias, cotidianidades y reconfiguraciones temporales en cuerpos femeninos.

La Organización Wayuu Munsurat fue conformada por un grupo de mujeres Wayuu después de la masacre de Bahía Portete, Guajira, ocurrida el 18 de abril de 2004, cuando un grupo paramilitar asesinó e hizo desaparecer a mujeres y niños del clan Uriana Epinayú, habitantes ancestrales de esta localidad. Los familiares sobrevivientes huyeron a Riohacha y a Maracaibo. La organización está conformada principalmente por mujeres víctimas de la masacre, cuyos principales objetivos han sido la lucha por una reparación diferente a la que propone el Estado y el retorno a su territorio.

La primera vez que tuve contacto con las mujeres de Portete fue en 2008, cuando realizaron el primer encuentro yanama en Bahía Portete, cuatro años después de la masacre. El principal objetivo de este encuentro era volver a estar ahí; dormir, cocinar, estar juntos nuevamente en el territorio, recordando a sus muertos y estando junto a ellos. Todo consistió en volver a estar ahí, en volver a hacer habitable ese lugar que había sido tocado por la violencia y el terror, aunque fuera solo por unos días. Durante esos días se realizaron recorridos por el territorio como una forma de volverlo a caminar. Mi acercamiento al caso de Portete me permitió ampliar aún más mis preguntas y aproximaciones con las que comencé, ya que me llevaron a explorar temas como el papel de los sueños en la forma de elaborar el duelo, el espacio de la perdida, la relación con los muertos y los espíritus en su vida cotidiana, las ambigüedades de las resistencias y las relaciones de género en las prácticas de duelo y mediación, entre tantas otras que fueron enriqueciendo mis perspectivas.

Espacios como los yanamas están abriendo posibilidades a otras relaciones y reconfiguraciones temporales y espaciales, a través de la perdida y el duelo como punto de partida de lo 
político. Desde esta perspectiva, me fui acercando a sus movilizaciones con base en un reconocimiento por parte del Estado, las instituciones, las comunidades indígenas y las organizaciones de mujeres. A la vez, reflexioné sobre cómo dejaban de ver las pérdidas y humanizaban tanto a los vivos como a los muertos al convocar una responsabilidad colectiva y compartida, al tiempo que participaba del encuentro, el exceso, las contradicciones, lo inconmensurable y lo que escapa a estas movilizaciones y reivindicaciones.

El desplazamiento de su territorio y el hecho no poder regresar a este es la pérdida más grande para la comunidad de Bahía Portete. Para ellos, el retorno es el principal motivo de su movilización política. La masacre y lo que esta generó y desplegó condujeron a una transformación de la comunidad por medio de la pérdida. Una política desde el duelo -a diferencia de una política desde la restauración y la eliminación del espacio de la pérdida- para lograr la fantasía de un mundo ordenado y de un espacio "superado."

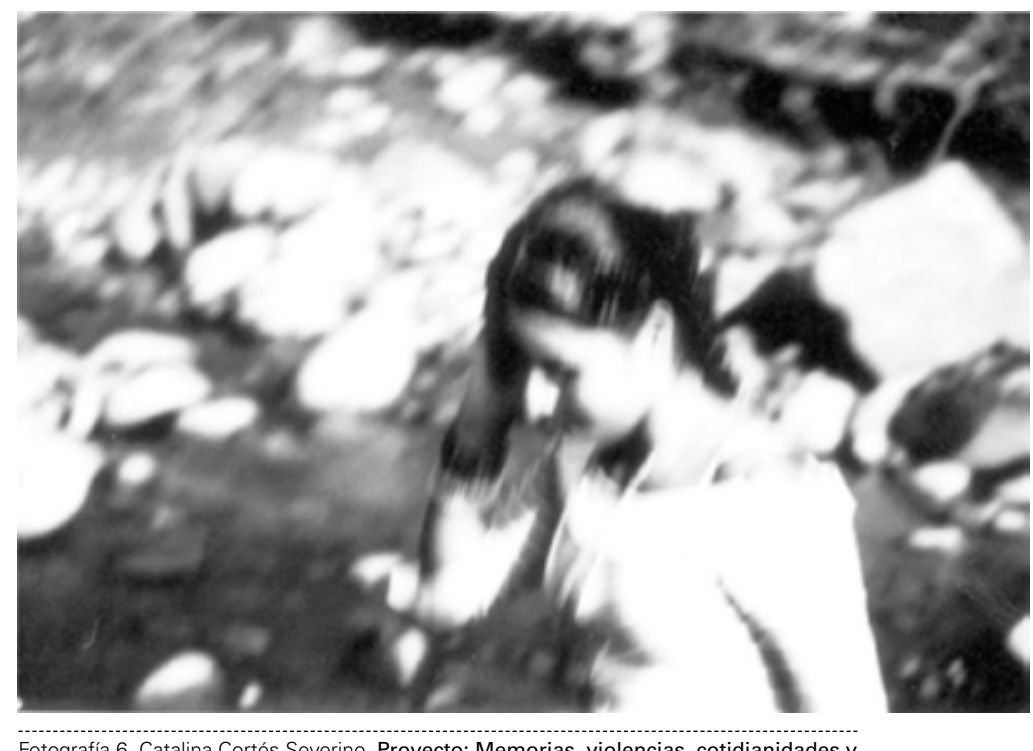

Fotografía 6. Catalina Cortés Severino. Proyecto: Memorias, violencias, cotidianidades y reconfiguraciones temporales en cuerpos femeninos.

Cuando estábamos recorriendo las casas 'violadas', -este es uno de los actos que se realizan en los yanama-, observamos los grafitis que evocaban la violencia y recordaban su huella en el presente. "Se borran pero vuelven a aparecer, los vuelven a dibujar. Siguen ahí para intimidarnos, para que uno sienta pena, para que uno sienta miedo (...) Aparecen de nuevo porque los paramilitares, bajo otra sigla, siguen allí y todavía tienen a las mujeres en la mira", dijo Débora Barros.

En las paredes de algunas casas fueron dejados estos grafitis amenazantes, que usaban imágenes de penetración y violación del cuerpo de una mujer por la boca, vagina y ano, y los nombres de una de las líderes del proceso. Este tipo de imágenes y mensajes hacen parte de esas formas de marcar el cuerpo como territorio, con fines de humillar, acallar y castigar a mujeres líderes, así como una transgresión del espacio doméstico -el lugar donde los cuerpos reposan, se aman, lloran y se construye parte de la cotidianidad-.

Ese lugar donde flota un perfume secreto que habla del tiempo perdido, del tiempo que ya nunca volverá, que habla también de un tiempo por venir, algún día, tal vez (...) el sufrimiento no viene de la pérdida de los bienes, sino del trastorno que produce esta intrusión violenta en la casa. (Giard, 2006, p. 158) 
Reinscripciones que vuelven a generar terror, desazón y desesperanza. ¿Cómo volver a vivir con esos cuerpos marcados y transgredidos? Si el cuerpo fue el territorio de inscripción del terror, ¿cómo puede ser el mismo territorio de regeneración y resignificación?

El cuerpo como territorio deja ver también esas huellas que quedan registradas en este $y$, al mismo tiempo, las nuevas formas de habitarlo -o de no poder habitarlo más-. Una de las ancianas de la comunidad, María Antonia Fince, a quien le toco ver cómo su hija era masacrada, se desplazó a Maracaibo y murió de tristeza. "Mi tía no aguanto tanta tristeza y se murió," me contó Sulimar. Esta anciana murió de pena moral en Maracaibo, sumida en los recuerdos, el dolor y la desesperación por haber perdido sus cosas, sus animales y de haber sido desplazada de su territorio. "Quedó en un estado de demencia, donde constantemente repetía que dónde estaban sus animales, su casa; ella murió hablando de sus chivos y de sus gallinas" (Sulimar). María Antonia murió el 28 de enero de 2010 en Maracaibo y fue enterrada en el cementerio de Bahía Portete.

El cuerpo es el lugar mediador entre el 'adentro' y el 'afuera', el lugar donde, por excelencia, la historia queda registrada a través de los sentidos. Los repertorios de la violencia lograron que esta quedara grabada en las fibras más íntimas del cuerpo, por medio de la transgresión de los cuerpos femeninos -transgresión que implica la reconfiguración de los espacios cotidianos, de sus formas de relacionarse con sus cuerpos y de habitarlos, transgresión que va desde las torturas y asesinatos cometidos hasta la violación de los espacios de intimidad; sus casas, donde el cuerpo se resguarda, habita y reposa.

La masacre de Portete transgredió las relaciones de género, causando una fractura en el orden social de la comunidad, su relación con el mundo de los muertos y su territorio. Como expuse anteriormente, el cuerpo de las mujeres fue un territorio donde se inscribió el terror. Una mujer contaba que el asesinato de mujeres y niños fue lo que hizo que "saliéramos corriendo como chivos y que nos uniéramos las mujeres para crear la organización en nombre de las compañeras muertas, ya que mataron mujeres que somos símbolo de paz, que damos la vida, mataron niños".

Cabe dejar sentado que la sociedad wayuu es de organización matriarcal, por lo que los crímenes expuestos resultan particularmente horrendos en esas circunstancias. Por ello, es necesario preguntarse de qué manera las diferentes violencias que han sufrido las mujeres wayuu han ido conformando las diferentes subjetividades, conformadas en medio de profundidades temporales que han hecho posible establecer otras formas de relacionarse, nuevos mecanismos de comunicación, de movilización política y, claro está, de habitar la cotidianidad. Así, es fundamental adentrarnos en la articulación entre violencia y subjetividad, deteniéndonos en las condiciones históricas que han hecho posibles ciertas experiencias políticas.

El accionar de la Organización Wayuu Munsurat tiene que ser entendido entre su 'campo de la experiencia' y sus 'horizontes de expectativa', para comprender sus apuestas por la reconfiguración de otros horizontes de reparación, de retorno y de relaciones, entre otros. Las movilizaciones políticas de la Organización están en la intersección entre discursos de antidiscriminación, explotación por las multinacionales, solidaridad de género, violencias históricas y luchas locales por el retorno al territorio y la reparación de las violencias sufridas como familia y comunidad. Pero lo político no se queda acá; también tiene que ver con las prácticas cotidianas de volver a habitar esos lugares de devastación. En estas prácticas se van dando los trabajos de transformación, las emergencias de nuevos significados, procesos formativos y afectos imposibles de definir y clasificar-lo que Williams (1978) llamaría "estructuras del sentir"-, donde 
se junta el pensamiento como sentimiento y el sentimiento como pensamiento -espacios para nuevas configuraciones de lo sensible y la intervención política-.

Para Karmen', la mamá de Debora y Telemina, parte de su agenda política ha sido la defensa de su territorio. Pero Karmen también ha sido la fuerza afectiva de la familia, como lo manifiesta Telemina: "mi mamá es la que nos ha dado alientos para seguir, desde su apoyo a la organización hasta la ayuda en la criada de nuestros hijos." Karmen adoptó a dos hijas de sus hermanas asesinadas que viven en su casa, en Riohacha, junto con su hija Telemina y las hijas de cada una. Katerin, una de las sobrinas adoptadas de Karmen -quien no regresaría a Portete sino después de cinco años, en un yanama, con su hija de dos años-, contaba que fue el apoyo de su tía, el nacimiento de su hija y la convivencia en la casa de Riohacha lo que le habían permitido vivir más tranquila después del asesinato de su mamá. Una casa habitada por las ausencias que conforman el presente y por las nuevas vidas que traen esperanza. También Memme, una de las hermanas de Karmen, adoptó a dos jóvenes después de la masacre: "ellas me han devuelto la vida, me han hecho renacer y poder vivir con todo ese dolor que cargo, además fue mi oportunidad de tener los hijos que nunca pude tener".

La capacidad de las mujeres de recomponer la cotidianidad y la solidaridad de género es parte fundamental de sus subjetividades políticas. Hoy en día, la mayoría de las víctimas en Colombia son mujeres, y es frecuente ver cómo entre ellas crean lazos de solidaridad y de apoyo con el objeto de realizar los duelos de manera colectiva. A partir de las pérdidas, se conforma su accionar político. Memme dice que "compartir el sufrimiento nos fortalece a las mujeres." Es ahí donde las mujeres de Portete han tenido una mayor fortaleza, porque han sido ellas las que reinstauren la cotidianidad, al preocuparse por lo que van a comer al día siguiente, cuidar de los niños, pensar dónde van a dormir, etc. Casi siempre depende de ellas la adaptación a las nuevas circunstancias.

Por lo tanto, el agenciamiento político de las mujeres de Portete no solo se puede entender desde su accionar público, sino también desde el ámbito de lo íntimo y lo privado; desde la resistencia en la cotidianidad y el modo en que estos ámbitos interactúan conjuntamente. Como dicen algunas de ellas, "uno de los acontecimientos más importantes del cuarto yanama fue volver a estar en Portete y poder volver a cocinar, a dormir ahí, simplemente volver a estar ahí todas juntas." Lo íntimo y lo público no son zonas separadas, sino zonas en contacto que se conforman mutuamente y que, en la conformación de las subjetividades políticas de las mujeres de Portete, están totalmente entrelazados.

"Las mujeres somos la conexión entre los indígenas y los blancos, y también entre los vivos y los muertos", dice Debora Barros. El pensamiento-sentimiento femenino es el que permite generar una zona de contacto entre los diferentes mundos. Es una zona fronteriza donde se puede negociar y crear puentes entre los diferentes mundos y sentidos y zona de contacto donde están emergiendo las subjetividades políticas en medio de las espirales de tiempo. Así, esto nos lleva a comprender mejor de qué manera en estos escenarios de violencia las mujeres son las que tienen mayor capacidad de volver a hacer habitable la cotidianidad a partir de gestos de duelo. El asesinato de mujeres y la exposición de sus cuerpos torturados produjo una total trasgresión en la comunidad de Bahía Portete, pero fueron también las mujeres quienes crearon el espacio de duelo desde la recogida de los cadáveres, la organización del entierro, el cuidado de los cementerios, la adopción de los hijos que quedaron huérfanos y la conformación de la Organización Wayuu Munsurat. 
Se trata pues de zonas de frontera que median entre lo sacro y lo profano, que logran mediar con las instituciones, participar en eventos con otras organizaciones, buscar fondos para la organización, cuidar de sus hijos, los cementerios, organizar sus hogares y comunicarse con sus muertos. Son subjetividades políticas que se conforman en esos puentes entre lo íntimo y lo público, en medio de voces que resuenan fuerte al pronunciar discursos de movilización política y denuncias a las injusticias sociales -como la de Débora en el tribunal de los pueblos-, y voces que suenan más bajito -como la de Karmen cuando nos contaba cómo sus hermanas asesinadas se le habían aparecido en el sueño y por eso se fumaba un tabaco por cada una-. Diferentes tonalidades de voces que son las que reconfiguran la distribución de lo que se puede escuchar, ver, denunciar y evadir.

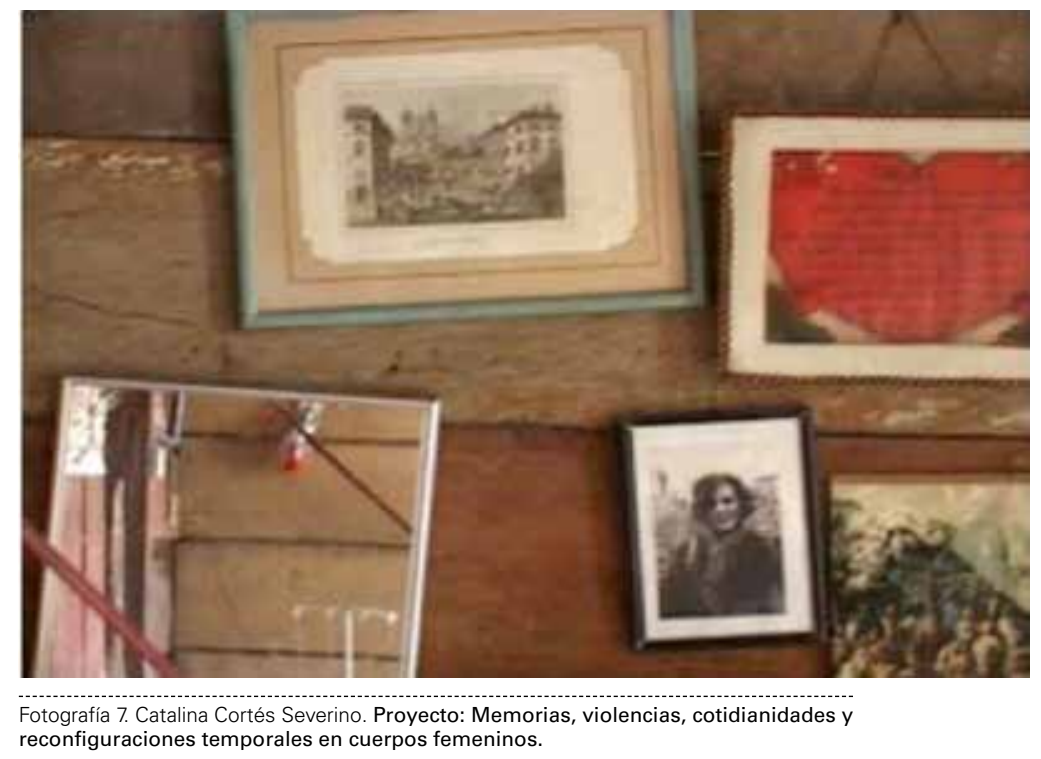

El rehabitar los espacios de devastación comienza desde la cotidianidad. Es el caso de la 'casa herida' de la Comunidad de Paz de San José de Apartadó, que fue ocupada para comenzar el retorno a Mulatos -una de las veredas de donde habían sido desplazadas muchas familias de la comunidad-. Esta casa tiene todas sus paredes bombardeadas, con grafitis de las brigadas del Ejército, los paramilitares y la guerrilla. A través de estos se puede entreleer y percibir las huellas de los agentes de tales escenarios de terror. Sin embargo, dicha casa comenzó a ser rehabitada por Marina, una de las mujeres líderes de la Comunidad de Paz, quien lleva consigo una historia de violencia inscrita en su cuerpo desde los años cincuenta, cuando su papá, su esposo y sus hijos fueron asesinados. Hoy en día, Marina vive en esa casa bombardeada. Impulsa el retorno de algunas familias de la comunidad a Mulatos, al tiempo que vive con la incertidumbre de ser desplazada nuevamente, debido a las amenazas que le llegan día a día. Ese gesto de ocupación, de rehabitar la casa herida, es una manera de volver a darle sentido a lo que fue totalmente fracturado y robado por el terror. Una forma de reconstruir y reparar su cotidianidad que permite plantear preguntas como estas: ¿cuáles son los actos que verdaderamente permiten 'continuar' en medio de esos residuos y fracturas que ha causado la violencia? ¿Qué desafíos nos plantean estos ejemplos para entender lo político y po-ético de las memorias?

Me interesa ver cómo esas violencias sedimentadas se encuentran inscritas en las materialidades del presente, cómo se han incorporado en la cotidianidad y en las relaciones de 
las personas, delineando las ruinas que permanecen y, sobre todo, las respuestas y formas de habitarlas. El caso de Marina no implica únicamente rehabitar una casa literalmente en ruinas, sino que toda su historia de vida ha estado marcada por las ruinas que han dejado las violencias de una región como Urabá, abandonada por el Estado. Violencias desencadenadas por los intereses de las economías legales e ilegales que buscan apropiarse de tierras y rutas, por la militarización de la región y, en general, por miles de violencias que se entrecruzan y que han dejado las ruinas sobre las que hoy la Comunidad de Paz intenta construir nuevos proyectos de vida.

La Comunidad de Paz es una comunidad de campesinos que se conformó como alternativa para vivir en medio de la guerra y resistir al desplazamiento de su territorio. Parte de sus estrategias de resistencia consisten en volver a habitar los lugares de los que fueron desplazados, a través de la ocupación de casas abandonadas, peregrinaciones de conmemoración a las personas que han sido asesinadas de la comunidad y el rearme de economías alternativas que les permitan ser autosuficientes, en lo posible.

La Comunidad de Paz está conformada principalmente por campesinos del interior de Antioquia y, más recientemente, por campesinos de Córdoba. No pretendo entrar en generalizaciones y universalizaciones deterministas, pero sí hay ciertos patrones culturales de las comunidades campesinas de esta región que considero relevantes. Entre ellos, el patriarcalismo, mezclado con un fuerte apego e influencia de la religión católica y donde el hombre, en ciertos ámbitos, tiene privilegios sobre la mujer. Existen varios casos de mujeres abandonadas, porque sus maridos se fueron con otras mujeres, de madres solteras y violencias intrafamiliares que eran naturalizadas, como contaba Juana, una mujer de aproximadamente treinta años de la comunidad:

Antes, las violencias contra las mujeres eran muchas, por parte de nuestros compañeros, nuestras familias y el mismo Estado. Hoy en día esto ha cambiado; nosotras, las mujeres, hemos entendido que tenemos derechos y valores, los mismos que los hombres. Antes, por ejemplo, mi pareja me podría violentar verbal o de otra forma, y yo me abstenía a decirlo o enfrentarlo, porque yo decía "si yo lo denuncio o me separo voy a quedar sola". Pero ahora yo ya no tengo miedo y de esto doy gracias a nuestros líderes, que nos han dado talleres sobre mujeres, y también a doña Brígida, que siempre nos ha ayudado a entender nuestra dignidad como mujeres.

Estos patrones han cambiado con el tiempo y han hecho emerger otro tipo de fenómenos, que van desde las luchas sindicales hasta el aumento de la cantidad de madres solteras, debido al asesinato de sus esposos y familiares.

Las mujeres jugamos un papel muy importante y más en estos momentos, porque muchas mujeres que nunca habían trabajado hoy les toca jugar ese doble papel de ser mamá y papá, les toca trabajar, sembrar para poder sostener sus hijos, entonces es ese doble rol tanto en la casa como en el trabajo con la comunidad. También tenemos más paciencia y capacidad de dialogar con la gente. No es una lucha solo por mí, sino por toda la comunidad. (Brígida, comunicación personal)

Estas relaciones de género están en constante mutación, en medio de nuevas emergencias y contradicciones. Esto complejiza los silencios sobre ciertas violencias y la potencialidad de ciertas escuchas que se yuxtaponen a otras. Por ejemplo, las memorias de la violencia que 
se ponen en escena por parte de la comunidad son las de los asesinatos de sus miembros, y el reclamo a una verdad y justicia es uno que va más allá de la justicia del Estado. Pero, ¿dónde quedan las memorias de esas violencias íntimas que hacen parte de los hogares y de las relaciones de género? ¿Dónde quedan guardados esos sufrimientos inscritos por esas violencias menos visibles y bulliciosas?

Dentro de la Comunidad de Paz no hay agendas específicas dirigidas la cuestión de género en términos de discursos y movilizaciones, pero al interior de esas resistencias y ese habitar de la cotidianidad hay prácticas e historias de vida que dejan ver otras emergencias de esas subjetividades femeninas que se han ido formando en medio de esos escenarios de cruces de violencias, como la historia de Brígida, Juana y Marina. Estas tres mujeres han vivido a través de las sedimentaciones violentas que han conformado al Urabá y sus perspectivas y formas de ser mujer han cambiado en medio de estas coyunturas. Brígida ha mantenido su lucha en los movimientos sindicales por los derechos de las mujeres trabajadoras, al igual que su labor como pedagoga entre las mujeres de la comunidad, para difundir sus derechos tanto en el trabajo como en la casa. Marina ha sido líder de la Comunidad de Paz, cabeza de familia e impulsadora del retorno a Mulatos. Ella comenzó ese retorno volviendo a habitar la 'casa herida'. Juana también es cabeza de familia. A ella le asesinaron a su primer compañero y, luego, el segundo se fue con otra mujer. Cada día lucha por sacar adelante a su hija -que padece de polio-y, paralelamente, trabaja para la Comunidad de Paz. Allí ve la única esperanza de continuar en su tierra. Estas nuevas emergencias de género no están articuladas a agendas o movilizaciones específicas, sino que van surgiendo en medio de la cotidianidad, donde muchas veces no hay lenguajes que las articulen o les otorguen nombres específicos; simplemente surgen en esos espacios donde las ruinas vuelven a tomar nuevos sentidos. "Aprender a mirar estas maneras de hacer, fugitivas y modestas, que a menudo son el único lugar de inventividad posible del sujeto". Esta cita de Giard (2006, p. 154) me hacía pensar más cercanamente en esas subjetividades femeninas, esculpidas a través del tiempo en medio de contradicciones, emergencias y residuos de lo vivido.

Brígida es de esas mujeres que se sientan con placer a contar su historia de vida y las historias de violencia que han cruzado el Urabá y de las cuales, de una u otra forma, ella ha hecho parte, desde la persecución a los sindicalistas hasta la entrada de los paramilitares y toda la maquinaria del terror que persiste hasta hoy. Una de los tardes que me senté a conversar con ella, desde la silla donde estaba sentada vi un dibujito, en un rincón de la casa, que era casi imperceptible donde se encontraba. Le pregunté sobre el dibujo y me dijo que lo había hecho su hija -quien había sido asesinada en 2005- y que ella no lo había movido del sitio donde ella lo había dejado. "Ese dibujo es como ella quería vivir en el campo, rodeado de animales y árboles, yo no lo he movido de ahí porque ella ahí lo dejo y ahí quiero que se quede" -deseos que habían quedado inscritos y congelados en ese dibujo y que un acto de barbarie había hecho desaparecer-. También me mostró una foto de ella y su hija, que tenía guardada en una caja. La había plastificado para que la humedad y el calor no la dañaran y deshicieran.

Sacó la caja de debajo de una cama que había en la mitad del cuarto, me dijo que ese era el lugar donde ella dormía con su hija y que había tenido que correrla para que ella no se le apareciera todas las noches. Se trata de intentos íntimos por preservar, guardar y cuidar esas memorias, para que no se vayan o se refundan por ahí. Son formas de vivir con la ausencia de su hija en medio de su cotidianidad y de hacerla presente a través de los trazos que quedan de ella. Cuando iba saliendo de su casa, me llevó al jardín, que estaba lleno de planticas que 
había sembrado y cuidado su hija. "Por eso este jardín es de lo que ha dado fuerzas para seguir viviendo". Memorias registradas e inscritas en matas, cajas, ángulos, sueños y objetos.

En medio de la tristeza que se sentía en el aire cuando Brígida me contaba de su hija, también repetía la necesidad de seguir luchando por no ser desplazados de sus tierras y continuar fortaleciendo la Comunidad de Paz y de entender la complejidad del conflicto, donde -como ella decía- "los que se enfrentan son campesinos: los paramilitares son campesinos, los guerrilleros y los mismos militares, entonces esta va más allá de malos y buenos". Brígida tiene un hijo que fue parte de la guerrilla y después desertó. Ahora hace parte de la Comunidad. Otro de sus hijos trabaja con Acción Social -el programa del Estado para los desplazados- en San José de Apartadó.

Esto nos permite acercarnos a la comunidad en medio de sus contradicciones, ambigüedades y emergencias, y no como un ensamblaje compacto y homogéneo. Así, fue el espacio de la cotidianidad lo que más me permitió adentrarme en esos espacios y tiempos, en los que más compartí con las mujeres y sus hijos. En medio del fogón, al lado del lavadero, en el patio trasero donde guardan a los animales y en sus cuartos fueron saliendo esas intimidades de la memoria y el olvido, al igual que las ambigüedades y complejidades que conforman el hecho de ser parte de la Comunidad de Paz.

Estas mujeres me hacían pensar, al mismo tiempo, en las complejidades y facilidades de la homogenización del sufrimiento que se pueden dar dentro de estas comunidades, al transformar el dolor del pasado en visiones de bien colectivo. Algunas veces puede ocurrir que la heterogeneidad de la experiencia individual del sufrimiento sea homogenizada, al visibilizar y legitimar unos sufrimientos por encima de otros. Tanto Marina como Juana y Brigida están convencidas y hacen parte del proyecto de la Comunidad de Paz, pero, al mismo tiempo cargan memorias, olvidos y sufrimientos íntimos que no están dentro de las agendas, al igual que formas de resistencia y resignificación de sus espacios y cuerpos que han emergido en medio de la cotidianidad, el silencio y la intimidad. En palabras de Das, "la cuestión de la relación entre sufrimiento individual y su transformación para fines de acción colectiva trae a coalición temas de profunda ambigüedad" (2008, p. 452).
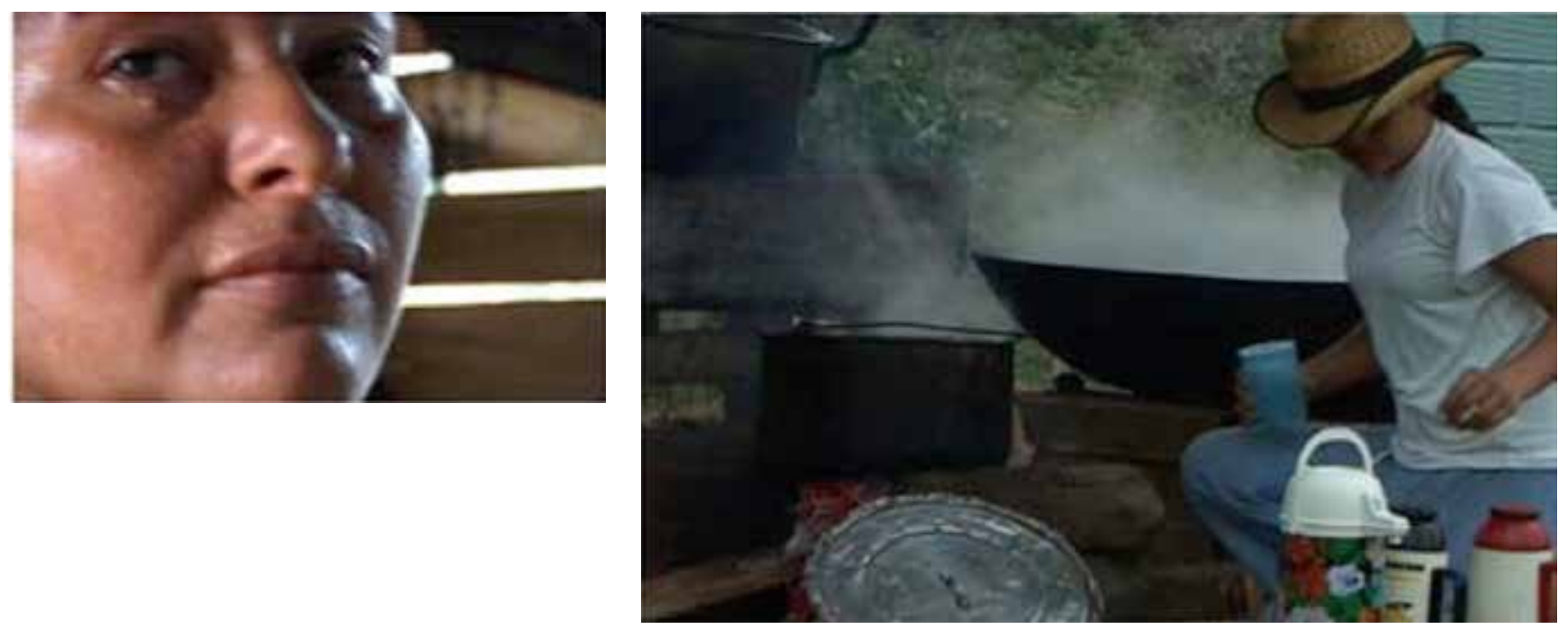

Fotografía 8 y 9. Autora Catalina Cortés Severino. Proyecto: Memorias, violencias, cotidianidades y reconfiguraciones temporales en cuerpos femeninos. 


\section{RUINA E IMAGINACIÓN: HACIA OTRAS EPISTEMOLOGÍAS Y FORMAS DE SER EN EL TIEMPO}

Termino con un llamado al futuro o futuros de la(s) ruina(s), más como devenir que como historia. De esta manera, parto de la necesidad de acercarme a esas ruinas mediante la generación de sentidos a través del olvido, el recuerdo y la imaginación. La imaginación consiste en lograr trabajar con esos fragmentos de la experiencia y las memorias, del tiempo-en-sí y ensamblarlos de diferentes maneras, para que permitan un cuestionamiento de la realidad más allá de las 'presencias', en interacción con el pasado y el devenir. Igualmente, esta perspectiva permite situarnos en esos intervalos complejos y contingentes que nos está presentando la aproximación a las ruinas, al abrirnos otros horizontes, sin fatalizar el pasado y determinar el futuro y evitar así la búsqueda de grandes relatos que impiden la complejización del presente.

Las ruinas no son imágenes del pasado; son parte de lo queda, de los muchos futuros y pasados que se han imaginado. No es, pues, una historia de destrucción cuya lección sea la de que no hay nada por hacer. Por el contrario, las ruinas muestran que, ante el futuro truncado, todo está por hacer. Es cuestión de imaginación política.

Así, lo político desde el duelo (Butler, 2006) implica situarse en un lugar de sentido más allá de las configuraciones institucionales del tiempo, que permita partir desde la ruina como lugar del pensamiento límite, abriendo campos para otras reconfiguraciones de lo temporal que creen nuevos espacios y tiempos alejados de consensos normalizadores y más cercanos a los disensos que hacen parte del duelo interminable inscrito en la ruina. Asimismo, esto nos debe situar en las contingencias del presente, donde se puedan visualizar posibilidades de futuros más humanos. Siguiendo a Grossberg (2000),

(...) we must embrace temporality in the celebration of imagination, as the attempt to discover new ways of belonging to time, to the past as well as to the present and the future. In this way we might also begin to imagine new forms and formations of a political will, and political collectivities capable of imagining new futures. (p. 159)

Derrida (1994) sitúa las políticas de la memoria en el ser-con-los espectros, es decir, en ese espacio entre la vida y la muerte donde aprendemos a vivir con esos otros que no están presentes, ya sea porque se fueron o porque todavía no han llegado y están por nacer. El llamado que hace Derrida hacia un ser-con-los espectros complejiza aún más los periodos llamados 'de transición', ya que muestra la necesidad de una responsabilidad hacia estos. Por consiguiente, se desarticula la posibilidad de ir de un 'pasado' a un 'presente', de la 'violencia' a la 'paz', al mismo tiempo que se impiden los discursos de 'erradicar' o 'superar' la violencia. Por el contrario, un ser-con-los espectros invita a pensar formas de vivir con los rastros y residuos que la violencia ha dejado y a re-imaginar otros futuros, para los que ya se fueron y para los que están por venir.

Actualmente, las amenazas continúan para la Comunidad de Paz y la Organización Wayuu Munsurat desde diferentes frentes. Estos escenarios existen en medio de la incertidumbre y la zozobra, de modo que en cualquier momento puede haber otro líder asesinado, nuevos desplazamientos, tierras militarizadas, megaproyectos de desarrollo, etc. Y todo esto en medio de un posconflicto que promete una reparación social y económica a través de la distribución de tierras. Son escenarios donde no hay garantías de nada, y donde continúan los actos de terror. Pero también son escenarios donde las movilizaciones y la cotidianidad de las personas que 
viven en medio de las ruinas, en sus contextos específicos y contingencias emergentes, dan espacio a otras posibilidades de futuros pensados y sentidos a partir de otras relaciones con el pasado.

\section{NOTAS}

No se presentan los apellidos de las mujeres que se mencionan en el artículo por motivos de seguridad.

\section{REFERENCIAS}

Benjamin, Walter. Sul concetto di Storia. Turín: Einaudi, 1997.

Butler, Judith. Precarious Life: The Power of Mourning and Violence. New York: Verso, 2006.

Chakrabarty, Dipesh. Provincializing Europe, Postcolonial Thought and Historical Difference. Princeton: Princeton University Press.

Das, Veena "Sujetos del dolor, agentes de la dignidad" En Francisco Ortega ed., Colección Lecturas CES, Bogotá: Centro de Estudios Sociales, Facultad de Ciencias Humanas, Universidad Nacional de Colombia, Instituto Pensar, Pontificia Universidad Javeriana, Medellín: Facultad de Ciencias Humanas y Económicas, Universidad Nacional, 2008.

Derrida, Jacques. The Work of Mourning. Chicago: The University of Chicago Press, 2001.

Franco, Jean. The Decline and Fall of the Lettered City: Latin America in the Cold War. Boston: Harvard College, 1999.

Giard, Luce. Hacer de Comer, en La invención de lo cotidiano II. Habitar, cocinar. Madrid: Universidad Iberoamericana, 2006.

Grossberg, Lawrence "History, Imagination and the Politics of Belonging: Between the Death and the Fear of History". En Gilroy, Paul, Grossberg, Lawrence y McRobbie, Angela, eds., Without Guarantees, in Honor of Stuart Hall). London, NewYork: Verso, 2000. 148-164

Rancière, Jacques. El desacuerdo. Buenos Aires: Política y Filosofía, 1996.

Richard, Nelly. Fracturas de la memoria. Buenos Aires: Siglo XXI Editores, 2007.

Williams, Raymond. Marxismo y literatura. Barcelona: Ediciones Península, 1978.

\section{Cómo citar este artículo:}

Cortés, Catalina. "Memorias, violencias, cotidianidades y reconfiguraciones temporales en cuerpos femeninos". Cuadernos de Música, Artes Visuales y Artes Escénicas, 10 (1), 79-94, 2015. http://dx.doi.org/10.11144/Javeriana.mavae10-1. mver 